\title{
SSIEM reflections 2004-2010: the growing stature of our society
}

\author{
Cornelis Jakobs
}

Published online: 15 October 2010

(C) The Author(s) 2010. This article is published with open access at Springerlink.com

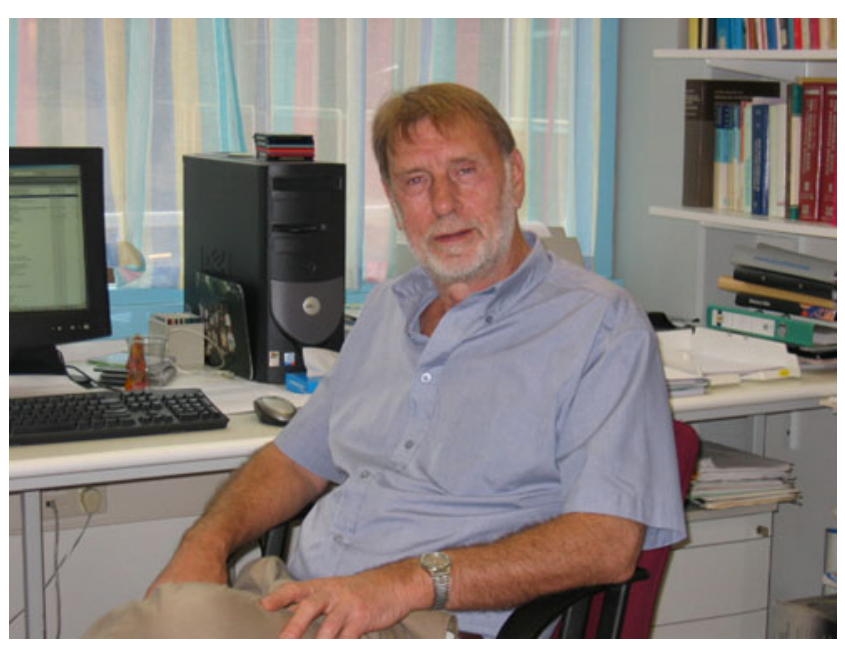

\section{Background}

Following my term as a regular council member (1999-2004) and president of the annual Society for the Study of Inborn Errors of Metabolism (SSIEM) symposium in Amsterdam, The Netherlands, in 2004, I was elected chairman of our society in 2004. This position was previously held by John Walter, who ended his successful term.

Continuity on council was assured with the retention of secretary Mick Henderson, treasurer Graham Shortland, and the Journal of Inherited Metabolic Disease (JIMD) chief editor Guy Besley remaining on council for at least an additional year, and this continuity was further assured

\section{Jakobs $(\bowtie)$}

Head Metabolic Unit, Department of Clinical Chemistry,

VU University Medical Center Amsterdam,

De Boelelaan 1117,

1081 HV Amsterdam, The Netherlands

e-mail: C.Jakobs@vumc.nl since I understood issues and processes from my previous years on council. Additional council members at that time were Nenad Blau, Ubaldo Caruso, Mick Champion, Philip Lee, Eli Anne Kvittingen, Jean-Marie Saudubray, and Isabel Tavares de Almeida.

Mick Henderson left council in 2005 and was replaced by Philip Lee, and Graham Shortland was replaced by Maureen Cleary in 2006. The year 2008 was a difficult period, with two key members leaving council. We were saddened to hear of the serious illness that led to the resignation of Philip Lee; we have been inspired by the way he has fought his illness. We also had to bid a-hopefully temporary-farewell to Maureen Cleary who moved to Singapore and was unable to continue as treasurer. Subsequently, Philip and Maureen were replaced by Philip Mayne (secretary) and Jim Bonham (treasurer), both of whom are still on council.

During my tenure as chair, we lost our valuable and longstanding Norwegian colleague, Eli Anne Kvittingen, who regretfully died in 2005. Other council members who left during that time after finishing their term(s) were Ubaldo Caruso, Mick Champion, and Jean-Marie Saudubray, and they were subsequently replaced by Jaume Campistol, Peter Clayton, Marjorie Dixon (as representative of the dieticians), Jutta Gaertner, and Victor Kozich, all of whom remain on council.

\section{JIMD}

One of the first actions of council during this time was to appoint a successor for Guy Besley as editor-in-chief of the journal. We invited individuals and/or groups to submit their interest for this post, together with a business plan for a new approach to the journal. Johannes Zschocke, Georg Hoffmann, and Verena Peters (all based in Heidelberg, Germany) presented a proposal that was subsequently 
chosen, and both Johannes and Georg were nominated as editors-in-chief, with Johannes representing the JIMD in council. Mike Gibson and Garry Brown continued as editors: Rodney Pollitt resigned from his editorial post after nearly 25 years. Council again expresses its deep and lasting gratitude to both Guy and Rodney for their guiding contributions and efforts in keeping JIMD current and scientifically sound. Their efforts were important in positioning the journal where it is today!

The journal format reverted to A4, and the look and color of the front page was modernized, with a new picture associated with a published paper on the front page of each issue. A large group of new communicating editors was elected to bring additional and new expertise to the review process. The editors continued to encourage submission of both research papers and reviews, and it seems that the addition of further expertise and a more critical review process resulted in an improvement in the journal's impact factor, which increased from 1.7 to 3.6 in these 5 years.

The new editorial board developed a strategy of making a distinction between printed articles that are of broad interest and solid scientific importance, compared with online reports that - although of more limited clinical or scientific interest - still merit documentation in the literature. This strategy has clearly been fruitful both in terms of impact factor and in assuring an opportunity for members of the society to have a voice in the journal. The editorial board and council have now made this strategy a permanent component to ensure the quality and standing of JIMD while at the same time facilitating publication of various articles of interest to SSIEM members. To this end, beginning in early 2011, JIMD will have a "sister" called JIMD Reports, which will contain all online articles. Full details are found in the JIMD "Instructions to Authors." Submissions to JIMD and JIMD Reports will be unchanged, facilitated through a single online portal. Council recognizes the effort and diligence of the editorial team in making these new changes and remains very supportive, having accordingly renewed the editorial team's tenure for an additional 5-year period. Also, council has just completed negotiations and signed an improved and more robust 5-year contract with Springer to continue publishing both JIMD and JIMD Reports.

\section{SSIEM Web site}

The SSIEM Web site, our portal for both the society and others interested in inherited metabolic diseases (especially parents and patients) was also in need of updating. This process was started in 2005. Ubaldo Caruso and Nenad Blau volunteered to work on this important project, and they were supported professionally by Michael McConnell of the Black
Cat Company. Michael handles both the day-to-day Web site activities and the electronic abstract submission and coordination during preparation for the annual symposium. Nenad Blau remains our Web manager and is responsible for further developments in updating and modernizing our site. We express our continued gratitude to Michael and Nenad for this important and long-standing effort.

\section{Annual symposia}

Our annual symposium has shown continued growth in the number of participants from increasingly diverse countries across the globe. A major increase occurred in 2004 in Amsterdam, with approximately 1,000 participants, and attendance continued to increase in Paris, France (2005); Hamburg, Germany (2007); Lisbon, Portugal (2008); and Istanbul, Turkey (2010); reaching more than 1,400 participants. All of these meetings had excellent scientific contributions and impact, in addition to attractive venues and social activities. With strong sponsor support, these symposia have never resulted in a deficit. I thank Jean Marie Saudubray, Rene Santer, Kurt Ullrich, Isabel Tavares de Almeida, and Turgay Coskun for their contributions and responsibilities as symposia presidents and for their valued collaboration and correspondence with council during their respective presidential terms.

\section{Administration}

The continued growth of the SSIEM, with increasing activities in the global inherited metabolic disease community, has necessitated professional administrative and secretarial support for council, directors, and trustees. Malcolm Heron stepped down as assistant to the honorary treasurer in December 2009 but continued to provide valuable and ever-present consultative service during 2010. Malcolm has given tremendous support to council and to the society membership for nearly two decades, and we are very grateful for his ongoing efforts on our behalf. On 1 January 2010, administrative responsibilities of SSIEM business matters transferred to our new administrative office in London, England. This office is shared with the Association of Clinical Biochemistry (ACB) at 130-132 Tooley Street. We now have our own SSIEM business logo and plaque on our office on the fifth floor of the Tooley Street suite and also on the outside street door. Council acknowledges the support that Graham Groome (now retired), Nic Law, and their collaborators who undertook SSIEM duties during the transition period. We are looking forward to a long-lasting and fruitful association with our colleagues in the ACB office. 


\section{ETAC}

Continued education and training in inherited metabolic disease (both from the clinical and laboratory standpoint) remains an important subject and focus for the society and for council. The SSIEM Education and Training Advisory Committee (ETAC) was created to advise and support SSIEM council in all aspects of training in inherited metabolic medicine. Paediatric Metabolic Medicine (PMM) is a recognised subsection of the European Academy of Paediatrics (EAP), which is a section of the European Union of Medical Specialists (UEMS). Although the SSIEM has no formal role within the European Union (EU) in developing and assessing training for laboratory scientists, SSIEM recognizes an important responsibility in this area. Consequently, ETAC now comprises both clinicians and laboratory scientists from our society. The ETAC Training and Advisory Committee is chaired by John Walter, with Jean-Marie Saudubray as senior advisor. Additional representatives are Andrew Morris, Vassili Valayannopoulos, Ute Spiekerkoetter, and Shamima Rahman with regard to clinical issues; and Brian Fowler, Mick Henderson, Christine Vianey-Saban, and Jorgen Bierau with regard to laboratory issues.

The responsibilities of ETAC are as follows:

- Formal assessment of clinical training centers and programs:

National societies may apply for centers within their country to be approved for training in PMM. This process requires a formal written application followed by a site visit by two members of ETAC. ETAC then submits its recommendation to EAP. As part of the process for training-center approval, the committee requires information about local training programs and trainee assessment. Syllabi are published on the SSIEM Web site for both clinical and laboratory training. Currently, ETAC is not responsible for assessing individual trainees but may be in a position to provide career guidance in the future. To date, three centers have been approved for training: Heidelberg, Germany; Prague, Czech Republic; and Innsbruck-Salzburg, Austria.

- SSIEM Academy:

ETAC organizes and supports the SSIEM Academy courses for training in areas of inherited metabolic disease. Council has allocated $€ 50,000$ for this activity since 2008 as an annual budget to cover ETAC's training expenses. In 2008, a 1-day concurrent course for both pediatricians and laboratory scientists took place in Lisbon just prior to the start of the annual SSIEM symposium. In October 2009, ETAC organized a successful 2-day Academy training course in conjunction with a European Research Network for evaluation and improvement of screening, Diagnosis, and treatment of Inherited disorders of Metabolism (ERNDIM) meeting in Basel, Switzerland; it was attended by 40 clinicians and 40 scientists, $25 \%$ of whom came from outside Europe. ETAC is holding the next SSIEM Academy meeting in Manchester, UK, on 4-5 October 2010, and in Amsterdam in 2011 (dates will be announced later).

Council plans to establish an administrative office for ETAC in Manchester in conjunction with ERNDIM, as outlined during last year's Annual General Meeting, and this is now planned for 2011. Council further plans to promote a continued expansion in training courses as part of the role of the Academy. ETAC will undertake further accreditation visits when requested, update the training syllabus on a regular basis, consider whether courses in inborn errors of metabolism are suitable for training needs - with ongoing evaluation of these needs - and organize further specific training programs as part of the SSIEM Academy.

\section{ICD-11}

In October 2009, the society received an invitation from Orphanet to contribute to the revision and update of the World Health Organization International Classification of Diseases (ICD-11), overseen by the Topic Advisory Group for Rare Diseases chaired by Segolene Ayme. Council invited Dr. Guy Besley to form a working group to develop a draft response on behalf of the society. Council acknowledges the extensive work that Guy contributed to preparing the report and agrees that if the revision steering group decides not to adopt SSIEM's recommended classification in part or in full, then the society will publish the classification on the SSIEM Web site and adopt the classification for its own use in JIMD as well as for training purposes.

\section{Adult Metabolic - and Dieticians' Groups}

Regional and national interest groups continue to grow, and council has received many enquiries from both Europe and abroad. In follow-up to these enquiries, council agreed to establish two special interest subgroups. An Adult Metabolic Group (SSIEM-AMG) will be led initially by Dr. Frederic Sedel, and a Dieticians' Group (SSIEM-DG) will be overseen by Dr. Reinhild Link. Both groups are open to all members of the society, and both will develop pages on the SSIEM Web site. Both groups will also have the opportunity to suggest topics for the annual meeting and will have access to and representation on council to bring their needs into an open forum. It is 
not council's intention to support the establishment of disorder-related interest groups, but it was felt that both adult metabolic inborn errors of metabolism and dietetics warranted special expertise and additional consideration.

\section{National societies}

The society actively encourages the formation of national societies that can communicate with each other through SSIEM, with the goal of raising awareness to metabolic diseases so that standards of care and research are continuously improved. Corresponding members bring forward the views of local national societies and report to council during the annual symposium. Nominations and opinions from corresponding members concerning SSIEM council activities are warmly welcomed. Information about national societies can be found on the SSIEM Web site, as can information concerning teaching and training activities. Countries who do not have local societies focused on inborn errors of metabolism can seek financial and organizational support from SSIEM, as well as guidance on educational needs and training/educational agendas from ETAC.

\section{ICIEM}

In recent years, dialogue and collaboration has continued to progress with the Society for Inherited Metabolic Disorders (SIMD), the US society focused on inherited errors of metabolism; the Australasian Society for Inborn Errors of Metabolism (ASIEM); the Japanese Society for Inherited Metabolic Diseases (JSIMD); and South American La Sociedad Latinoamericana de Errores Innatos del Metabolismo y Pesquisa Neonatal (SLEIMPN) under the umbrella of the International Congress of Inborn Errors of Metabolism (ICIEM). Recent ICIEM meetings were held in Brisbane, Australia (2003); Tokyo, Japan (2006); and San Diego, USA (2009). During those years, SSIEM did not hold its own annual meeting. Council and corresponding members noted that the opinion of SSIEM members remains quite varied concerning the relationship between the SSIEM and the ICIEM. It has appeared at times that a broad consensus of discussion was absent in the decision-making process for ICIEM meetings, and many European SSIEM members were concerned that a European conference on inborn errors of metabolism was not held during the ICIEM congress years. To improve involvement in decision making and to continue to seek consensus where possible, a constitution was developed for the International Organizing Committee (IOC; the oversight council for ICIEM), and included two nominated representatives of each society. Furthermore, the frequency of ICIEM meetings has been changed to every 4 years instead of
3 years. The next meeting will be in Barcelona, Spain, in 2013, organized by SSIEM; and the following venue will be Brazil in 2017. SSIEM will re-evaluate its position on ICIEM after the 2017 meeting. Current SSIEM representatives on the IOC are Peter Clayton and myself. I have been elected chairman of the IOC through to the Barcelona meeting in 2013.

\section{Personal reflections}

It is remarkable that 11 years have passed so quickly during my tenure as both a member and then chairman of council. This decade has been a period of growth both for the society and for me personally. There have been challenges at times: some political, some monetary, and others concerning interpersonal relationships. I have learned during this time to "listen" more and work toward the best compromises - those that benefit both my colleagues and co-workers-but always with the needs and objectives of the society first in my mind! The number of hours invested (e.g., travel, meetings, discussion, paperwork) have been too many to remember, but my main goals of seeing our society grow-becoming ever more diverse and inclusive each year-and having our scientific and professional stature continue to increase, have certainly been achieved. I hope you agree that these hours invested have been worthwhile. Where will the future take SSIEM? Of course, none of us know for sure, but I see an expansion of our scientific network, more and extended advocacy for patients with inborn errors of metabolism for whom our members provide care, and increasing recognition of SSIEM as a prominent component and cornerstone in the care and support of patients with inherited metabolic disorders. And, in the end, serving the needs of our patients in the most comprehensive and compassionate way must always be the primary objective for us all! My fondest farewells to colleagues and friends as I now step aside, with the belief that I have left the society stronger after 11 years and certainly in the best and most competent hands.

I thank my fellow council members for all their support and all of you as members of our society for your confidence. It has been an honor to serve the SSIEM. My successor is Peter Clayton from London: I wish Peter good luck and the same support I have received.

Acknowledgements I am most grateful to Mike Gibson, Philip Mayne, and John Walter for correcting, editing, and improving this SSIEM Column

Open Access This article is distributed under the terms of the Creative Commons Attribution Noncommercial License which permits any noncommercial use, distribution, and reproduction in any medium, provided the original author(s) and source are credited. 